\title{
Analisis Faktor Indeks Harga Konsumen Kota Semarang
}

\author{
Novia Nafisah ${ }^{1}$, Respatiwulan ${ }^{2}$ \\ ${ }^{1,2}$ Program Studi Statistika, Universitas Sebelas Maret \\ novianafisah@gmail.com,rrespatiwulan@yahoo.co.id
}

\begin{abstract}
The Consumer Price Index (CPI) can describe consumption patterns in the community. The CPI is also used to calculate inflation rates that reflect a country's economic conditions. The CPI for sub-expenditure consists of 7 groups divided into 35 sub-groups. Factor analysis on CPI was conducted to reduce variables, to identify underlying factors, and to classify variables in the Semarang City CPI expenditure group from January 2014 to August 2017. As the result, there is only one underlying factor, namely the primary needs of urban communities with cumulative variance value of $88.509 \%$, eigenvalues of 23.012 consisting of 27 subgroup variables.
\end{abstract}

Keywords : Consumer Price Index (CPI), factor analysis, eigen value

\section{Pendahuluan}

Kehidupan manusia tidak dapat dipisahkan dari kegiatan ekonomi dalam rangka memenuhi kebutuhan hidupnya. Perkembangan ekonomi regional merupakan gambaran awal untuk melihat tingkat kesejahteraan masyarakat di suatu daerah. Di banyak negara, para pakar hingga saat ini masih menyepakati bahwa indikator untuk menentukan tingkat stabilitas ekonomi suatu negara adalah Indeks Harga Konsumen (IHK). IHK dapat memberikan informasi mengenai perkembangan harga barang dan jasa (komoditas) yang dibayar oleh konsumen atau masyarakat khususnya masyarakat kota. Perubahan data IHK merupakan indikator ekonomi makro yang penting untuk memberikan gambaran tentang laju inflasi suatu daerah dan lebih jauh lagi dapat menggambarkan pola konsumsi masyarakat.

Paket komoditas yang digunakan dalam menyusun IHK diperoleh dari survei pengeluaran rumah tangga yaitu Survei Biaya Hidup (SBH). IHK dapat dipengaruhi oleh perubahan harga pasar. Oleh karena itu survei yang digunakan adalah survei pada pasar yang memenuhi syarat, pasar tersebut harus benar-benar layak dijadikan tempat survei sebab dijangkau oleh masyarakat luas. Indeks Harga Konsumen (IHK) pada Kelompok Pengeluaran terdiri dari 7 macam kelompok dan terbagi menjadi 35 sub-sub kelompok.

Struktur ekonomi yang kuat dalam pembangunan perekonomian dapat diwujudkan dengan adanya keseimbangan dan keserasian yang ideal antara berbagai kelompok pengeluaran. Dari sekian banyak sub kelompok pengeluaran tersebut, hanya yang memberikan kontribusi besar yang dibahas yakni seluruh sub pengeluaran kecuali 
pada sub pengeluaran pendidikan, rekreasi dan olahraga, karena pada sub pengeluaran tersebut terdapat data yang sama atau konstan dari waktu ke waktu sehingga memiliki variansi 0 .

Untuk mengetahui, meringkas dan mereduksi sub kelompok Pengeluaran (variabel yang akan diteliti) yang memberikan kontribusi besar terhadap laju inflasi, digunakanlah metode analisis faktor.

\section{Landasan Teori}

2.1. Survei Biaya Hidup (SBH). SBH merupakan survei pengeluaran konsumsi rumah tangga di daerah perkotaan untuk mendapatkan pola konsumsi masyarakat sebagai bahan penyusunan diagram timbang dan paket komoditas yang baru dalam perhitungan IHK. SBH telah dilaksanakan oleh BPS pertama kali pada tahun 1977/1978. Selanjutnya pada tahun 1988/1989, 1996, 2002, 2007 dan 2012. SBH tahun 2018 ini adalah merupakan yang ke 7 kali dilaksanakan di Indonesia. Pada tahun 2018, terdapat enam kota metropolitan di Jawa Tengah yang menyelenggarakan SBH yakni Cilacap, Kudus, Semarang, Purwokerto, Surakarta, dan Tegal.

2.2. Indeks Harga Konsumen. IHK adalah angka indeks yang menggambarkan perubahan harga barang dan jasa yang dikonsumsi oleh masyarakat atau rumah tangga secara umum pada suatu periode waktu yang telah ditetapkan. Periode waktu yang telah ditetapkan digunakan sebagai dasar perhitungan atau pembanding yang ditentukan sama dengan 100 .

Seperti yang telah diketahui yang dimaksud dengan IHK adalah angka yang menggambarkan perbandingan harga konsumen yang terjadi pada dua periode waktu yang berbeda. Harga konsumen mencakup harga semua jenis barang atau jasa yang dikonsumsi masyarakat secara umum diantaranya meliputi: kelompok bahan makanan; makanan jadi, minuman, rokok, dan tembakau; kelompok perumahan; kelompok sandang; kelompok kesehatan; kelompok pendidikan; rekreasi dan olah raga; dan kelompok transportasi dan komunikasi [1].

2.3. Analisis Faktor. Proses analisis faktor mencoba menemukan hubungan (interrelationship) antar sejumlah variabel-variabel yang saling independen satu dengan yang lain sehingga bisa dibuat satu atau beberapa kumpulan variabel yang lebih sedikit dari sejumlah variabel awal [2]. Selain digunakan untuk mengetahui hubungan antar variabel, aplikasi penggunaan analisis faktor memiliki tujuan sebagai berikut [3] : 
a. Identifikasi faktor yang mendasari

Salah satu penggunaan yang paling penting dari analisis faktor adalah untuk mengidentifikasi faktor yang mendasari dari sekumpulan besar variabel. Dengan mengelompokkan sejumlah besar variabel ke dalam jumlah yang lebih kecil dari kumpulan yang homogen dan membuat variabel baru yang disebut faktor yang mewakili sekumpulan variabel tersebut dalam bentuk yang lebih sederhana, maka akan lebih mudah untuk diinterpretasikan.

b. Penyaringan variabel (screening of variables)

Penggunaan penting dari analisis faktor selanjutnya adalah penyaringan variabel untuk disertakan dalam penelitian statistik selanjutnya, seperti analisis regresi atau analisis diskriminan.

c. Meringkas data (summary of data)

Penerapan analisis faktor selanjutnya adalah untuk mengekstrak sedikit atau banyak faktor sesuai yang diinginkan dari satu set variabel.

d. Memilih variabel (sampling of variables)

Penggunaan teknik analisis faktor selanjutnya adalah untuk memilih sekelompok kecil perwakilan variabel yang representatif, walaupun sebagian besar variabel berkorelasi, hal ini bertujuan untuk memecah berbagai masalah praktis.

e. Pengelompokan objek (clustering of objects)

Selain mengidentifikasi kesamaan antara variabel, analisis faktor dapat digunakan untuk mengelompokkan objek. Dalam prosedur ini, sering disebut analisis faktor sebagai inverse, sebuah sampel individu diukur pada sejumlah variabel acak, dan dikelompokkan ke dalam kelompok yang homogen berdasarkan antar korelasinya.

Secara matematis, analisis faktor mirip dengan regresi linear berganda, yaitu bahwa setiap variabel dinyatakan sebagai suatu kombinasi linear dari faktor yang mendasari (underlying factors). Jumlah (amount) varian yang disumbangkan oleh suatu variabel dengan variabel lainnya yang tercakup dalam analisis disebut communality. Kovariasi antara variabel yang diuraikan, dinyatakan dalam suatu common factors yang sedikit jumlahnya ditambah dengan faktor yang unik untuk setiap variabel. Faktor-faktor ini tidak secara jelas terlihat (not overly observed). Model analisis faktor diberikan pada persamaan berikut : 


$$
\begin{gathered}
X_{1}-\mu_{1}=\lambda_{11} F_{1}+\lambda_{12} F_{1}+\cdots+\lambda_{1 q} F_{q}+\varepsilon_{1} \\
X_{2}-\mu_{2}=\lambda_{21} F_{2}+\lambda_{22} F_{2}+\cdots+\lambda_{2 q} F_{q}+\varepsilon_{2} \\
\cdots \\
X_{p}-\mu_{p}=\lambda_{p 1} F_{p}+\lambda_{p 2} F_{p}+\cdots+\lambda_{p q} F_{q}+\varepsilon_{p}
\end{gathered}
$$

dengan

$\mu \quad$ : rata-rata dari variabel ke- $i$

$\varepsilon_{i} \quad$ : faktor spesifik (specific factors) ke- $p$

$\lambda_{i} \quad$ : loading untuk variabel ke-i pada faktor ke-j.

$F_{j} \quad:$ common factors ke-j

$i: 1,2, \ldots, p$ dan $j: 1,2, \ldots, q$

Faktor yang unik tidak berkorelasi dengan sesama faktor yang unik dan juga tidak berkorelasi dengan common factor. Common factor sendiri bisa dinyatakan sebagai kombinasi linear dari variabel-variabel yang terlihat/terobservasi (the observed variables) hasil penelitian lapangan.

Menurut Johnson et al. [4] bagian dari varian variabel ke- $i$ dan $m$ common factor disebut komunalitas ke-i yang merupakan jumlah kuadrat dari loading variabel ke-i pada $m$ common factor dengan rumus komunalitas diberikan pada persamaan berikut

$$
h_{i}^{2}=l_{i 1}^{2}+l_{i 2}^{2}+\cdots+l_{i m}^{2}
$$

Hubungan antara varians variabel asal dengan varians faktor dan error adalah sebagai berikut:

$$
\begin{aligned}
\operatorname{Var}\left(X_{t}\right) & =h_{i}^{2}+\Psi_{i} \\
& =\left(l_{i 1}^{2}+l_{i 2}^{2}+\cdots+l_{i m}^{2}\right)+\Psi_{i}
\end{aligned}
$$

Besarnya bobot $l_{\mathrm{ij}}$ dapat diduga dengan menggunakan metode komponen utama maupun kemungkinan maksimum (maximum likelihood). Metode komponen utama terbagi menjadi dua metode yakni non-iteratif dan iteratif. Dugaan nilai $l_{\mathrm{ij}}$ yang diperoleh dengan metode non-iteratif diberikan pada persamaan berikut:

$$
l_{i j}=\frac{a_{j i} \sqrt{\lambda_{j}}}{s_{x_{j}}} \text { atau } l_{i j}=a_{j i} \sqrt{\lambda_{j}}
$$


dengan

$l_{i j} \quad$ : bobot (loading) dari variabel asal ke-i pada faktor ke-j

$a_{j i} \quad$ : koefisien variabel asal ke- $i$ untuk komponen utama ke-j

$\lambda_{j} \quad$ : eigen value untuk komponen utama ke- $j$

$s_{x j} \quad$ : simpangan baku variabel asal ke-j

Terdapat beberapa tahapan analisis faktor yang perlu dilakukan guna mendapatkan faktor baru.

\subsubsection{Initial Solution}

Solusi awal dilakukan untuk menguji kelayakan analisis, yaitu untuk melihat terpenuhinya asumsi sebagai syarat dapat dilakukan analisis faktor. Kriteria untuk mengetahui apakah suatu data dapat dianalisis faktor ditentukan oleh dua hal yaitu harga koefisien Kaiser-Meyer-Olkin (KMO) dan uji Bartlett.

a. Uji Bartlett

Uji Bartlett bertujuan untuk mengetahui apakah terdapat hubungan antar variabel. Jika variabel $X_{1}, X_{2}, \ldots, X_{p}$ independen (bersifat saling bebas), maka matriks korelasi antar variabel sama dengan matriks identitas. Uji Bartlett memiliki keakuratan (signifikansi) yang tinggi, $p$-value kurang dari 0,00000 menunjukkan bahwa matriks korelasi cocok untuk analisis faktor.

\section{b. Uji KMO}

Uji Kaiser-Meyer-Olkin (KMO) diperlukan untuk melihat kecukupan sampel yang dianalisis (sampling adequacy). Menurut Kaiser [5], nilai KMO ini diperoleh dengan membandingkan besarnya koefisien korelasi terobservasi dengan besarnya koefisien korelasi parsial. Jika nilai KMO antara 0,8 dan 1 menunjukkan bahwa sampel cukup. Jika nilai KMO kurang dari 0,5 menunjukkan bahwa sampel tidak cukup dan perlu dilakukan tindakan perbaikan. Nilai KMO mendekati nol berarti bahwa ada korelasi parsial yang besar dibandingkan dengan jumlah korelasi yang ada.

Menurut Subhash Sharma [6], kriteria nilai KMO ditunjukkan pada Tabel 2. 
Tabel 2. Ukuran KMO

\begin{tabular}{cc}
\hline Ukuran KMO & Rekomendasi \\
\hline$\geq 0,90$ & Baik sekali \\
$\geq 0,80$ & Baik \\
$\geq 0,70$ & Sedang \\
$\geq 0,60$ & Cukup \\
$\geq 0,50$ & Kurang \\
$<0.50$ & Ditolak
\end{tabular}

Jika nilai KMO kurang dari 0,50 maka analisis faktor tidak sesuai untuk variabelvariabel tersebut. Variabel yang memiliki nilai MSA kurang dari 0,5 perlu dihilangkan lalu dilakukan pengujian ulang hingga seluruh variabel memiliki nilai MSA kurang dari 0,5 .

\subsubsection{Extraction}

Proses inti dari analisis faktor yakni ekstraksi yang dilakukan pada faktor yang memiliki nilai KMO lebih dari 0,5 sehingga terbentuk satu atau lebih faktor. Proses ekstraksi dilakukan untuk mendapatkan lebih sedikit faktor (eigenvalues factor) dari sejumlah variabel dan sumbangan faktor terhadap keseluruhan variabel (total variance explained). Terdapat beberapa metode untuk melakukan ekstraksi. Dalam penelitian ini menggunakan salah satu metode yaitu analisis komponen utama (principal component analysis). Beberapa prosedur yang bisa digunakan yakni

a. Penentuan apriori

Proses ekstraksi dengan penentuan apriori dilakukan dengan cara menentukan jumlah faktor baru yang ingin dibentuk.

b. Penentuan berdasarkan eigenvalues

Di dalam pendekatan ini, hanya faktor dengan eigenvalues lebih besar dari 1 (satu) yang dipertahankan, kalau lebih kecil dari satu, faktornya tidak diikutsertakan dalam model. Suatu eigenvalues menunjukkan besarnya sumbangan dari faktor terhadap varian seluruh variabel asli. 
c. Penentuan berdasarkan scree plot

Scree plot merupakan suatu plot dari eigenvalue sebagai fungsi banyaknya faktor, dalam upaya untuk ekstraksi. Scree plot seperti garis yang patah-patah. Bukti hasil eksperimen menunjukkan bahwa titik pada tempat di mana the scree mulai terjadi, menunjukkan banyaknya faktor yang benar.

d. Penentuan didasarkan pada persentase varian

Di dalam pendekatan ini, banyaknya faktor yang diekstraksi oleh faktor mencapai suatu level tertentu yang memuaskan. Besarnya kumulatif persentase varian sebagai pedoman/ petunjuk yang disarankan untuk menghentikan ekstraksi faktor paling sedikit $60 \%$ atau $75 \%$ dari seluruh varian variabel asli.

\section{e. Penentuan berdasarkan split-half reliability}

Sampel dibagi menjadi dua, analisis faktor dilakukan pada masing - masing bagian sampel tersebut. Hanya faktor dengan faktor loading yang sesuai pada kedua sub-sampel yang dipertahankan, maksudnya faktor-faktor yang dipertahankan memang mempunyai faktor loading yang tinggi pada masing- masing bagian sampel.

\section{f. Penentuan berdasarkan uji signifikan}

Dimungkinkan untuk menentukan signifikansi statistik untuk eigenvalues yang terpisah dan dipertahankan faktor-faktor yang memang berdasarkan uji statistik eigenvaluenya signifikan pada $\alpha$ sebesar 5\% atau $1 \%$. Penentuan banyaknya faktor dengan cara ini ada kelemahannya, khususnya dengan ukuran sampel yang besar.

\subsubsection{Rotation}

Rotasi adalah proses memutar sumbu mendekati koordinat titik-titik variabel. Proses ekstraksi hanya menentukan jumlah faktor yang meringkas keseluruhan variabel, namun belum menentukan distribusi variabel-variabel ke dalam faktor-faktor yang meringkasnya. Rotasi melakukan proses yang belum dilakukan oleh prosedur ektraksi dengan menarik butir-butir kedalam faktor-faktor terdekat. Tujuan dari rotasi faktor ini agar dapat memperoleh struktur faktor yang lebih sederhana agar mudah diinterpretasikan. Ada beberapa metode rotasi faktor yang bisa digunakan yaitu:

1) varimax method merupakan metode rotasi orthogonal untuk meminimalisasi jumlah indikator yang mempunyai factor loading tinggi pada tiap faktor. 
2) quartimax method merupakan metode rotasi untuk meminimalisasi jumlah faktor yang digunakan untuk menjelaskan indikator

3) equamax method merupakan metode gabungan antara varimax method yang meminimalkan indikator dan quartimax method yang meminimalkan faktor.

\subsubsection{Interpretation}

Setelah diperoleh sejumlah faktor yang valid, selanjutnya perlu menginterprestasikan nama-nama faktor, mengingat faktor merupakan sebuah konstruk dan sebuah konstruk menjadi berarti kalau dapat diartikan. Interprestasi faktor dapat dilakukan dengan mengetahui variabel-variabel yang membentuknya. Interprestasi dilakukan dengan judgment. Karena sifatnya subjektif, hasil bisa berbeda jika dilakukan oleh orang lain.

\section{Metode Penelitian}

Data yang digunakan yakni data Indeks Harga Konsumen (IHK) Kota Semarang pada bulan Januari 2014 sampai dengan Agustus 2017. Terdapat 7 kelompok pada data IHK yang terbagi menjadi 35 sub kelompok. Diambil 30 dari 35 Sub kelompok yang ada dan digunakan sebagai data analisis faktor IHK Kota Semarang. Pada setiap sub kelompok, digunakan data IHK per bulan dari Januari 2014 sampai Agustus 2017. Pada penelitian ini, data kelompok pendidikan, rekreasi, dan olahraga tidak digunakan karena kelompok tersebut dianggap kurang memberikan pengaruh yang signifikan. Metode yang digunakan yakni analisis faktor serta menggunakan metode rotasi varimax. Data dalam penelitian ini berupa data sekunder yakni data IHK Kota Semarang yang diperoleh dari Badan Pusat Statistik (BPS) Provinsi Jawa Tengah.

\section{Hasil dan Pembahasan}

Analisis data dilakukan menggunakan software SPSS dengan metode analisis faktor guna mengidentifikasi faktor yang terbentuk dan mengetahui besarnya nilai komunalitas dari 30 variabel sub kelompok IHK Kota Semarang yang digunakan. Terdapat beberapa langkah dalam analisis ini, yakni:

\subsection{Initial Solution}

a. Uji Bartlett's

1) $H_{0}:$ Matriks korelasi sama dengan matriks identitas

$H_{a}$ : Matriks korelasi tidak sama dengan matriks identitas 
2) Tingkat signifikansi $\alpha=5 \%$

3) Daerah kritis $H_{0}$ ditolak apabila $p$-value kurang dari $\alpha$ sama dengan 0,05

4) Statistik Uji

Berdasarkan output dari SPSS diperoleh nilai p-value sama dengan 0,000

5) Kesimpulan

Karena nilai $p$-value kurang dari 0,05 maka $H_{o}$ ditolak yang berarti analisis multivariat layak untuk digunakan terutama analisis faktor pada data IHK Kota Semarang.

b. Uji KMO

Diperoleh nilai KMO sebesar 0,625 yang berarti sampel yang akan dianalisis cukup untuk digunakan.

Berdasarkan output software SPSS, terdapat beberapa variabel yang nilai Measure Sampling Adequacy (MSA) kurang dari 0,5 maka variable tersebut harus dihilangkan atau dikeluarkan dari model. Setelah variabel dikeluarkan, dilakukan pengujian ulang terhadap nilai MSA semua variabel dan nilainya lebih dari 0,5. Pada analisis ini terdapat beberapa variabel pada pengujian pertama yang memiliki nilai MSA kurang dari 0,5 yakni variabel bumbu, lemak dan minyak, komunikasi dan pengiriman dengan nilai MSA berturut-turut yakni 0,484; 0,463; 0,498. Selanjutnya variabel tersebut dikeluarkan atau dihilangkan dari model. Dilakukan pengujian kedua terhadap seluruh nilai MSA 27 variabel yang tersisa. Dari hasil output SPSS nilai KMO sebesar 0,819 dan nilai signifikansi 0,000 yang berarti sampel sangat cukup dan analisis faktor layak untuk digunakan. Dilihat dari nilai MSA seluruh variabel lebih dari 0,5 sehingga dapat dilanjutkan ke analisis selanjutnya.

\subsection{Ekstraksi faktor}

Communalities pada dasarnya adalah jumlah varian (bisa dalam prosentase) dari suatu faktor mula-mula yang bisa dijelaskan oleh faktor yang ada. Angka initial disini untuk mengetahui varian dari suatu faktor dengan masing-masing variabel mempunyai angka 1 yang menunjukkan jumlah varians faktor tersebut. Sedangkan angka extraction adalah untuk mengetahui jumlah varians dari suatu faktor mula-mula yang bisa dijelaskan oleh faktor yang terbentuk. 
Berdasarkan output SPSS, nilai komunalitas setiap variabel dapat dilihat pada Tabel 3.

Tabel 3. Nilai komunalitas setiap variabel

\begin{tabular}{|c|c|c|c|}
\hline No. & Variabel & Komunalitas & Interpretasi \\
\hline 1. & $\begin{array}{l}\text { Padi, umbi, dan } \\
\text { hasilnya }\end{array}$ & 0,867 & $\begin{array}{l}\text { Faktor yang terbentuk dapat menjelaskan } \\
86,7 \% \text { varians dari variabel padi, umbi, } \\
\text { dan hasilnya. }\end{array}$ \\
\hline 2. & Daging & 0,463 & $\begin{array}{l}\text { Faktor yang terbentuk dapat menjelaskan } \\
46,3 \% \text { varians dari variabel daging. }\end{array}$ \\
\hline 3. & Ikan segar & 0,930 & $\begin{array}{l}\text { Faktor yang terbentuk dapat menjelaskan } \\
93 \% \text { varians dari variabel ikan segar. }\end{array}$ \\
\hline 4. & Ikan awet & 0,975 & $\begin{array}{l}\text { Faktor yang terbentuk dapat menjelaskan } \\
97,5 \% \text { varians dari variabel ikan awet. }\end{array}$ \\
\hline 5. & Telur dan susu & 0,848 & $\begin{array}{l}\text { Faktor yang terbentuk dapat menjelaskan } \\
84,8 \% \text { varians dari variabel ikan telur dan } \\
\text { susu. }\end{array}$ \\
\hline 6. & Sayur & 0,937 & $\begin{array}{l}\text { Faktor yang terbentuk dapat menjelaskan } \\
93,7 \% \text { varians dari variabel sayur. }\end{array}$ \\
\hline 7. & $\begin{array}{l}\text { Kacang- } \\
\text { kacangan }\end{array}$ & 0,985 & $\begin{array}{l}\text { Faktor yang terbentuk dapat menjelaskan } \\
98,5 \% \text { varians dari variabel kacang- } \\
\text { kacangan. }\end{array}$ \\
\hline 8. & Buah-buahan & 0,932 & $\begin{array}{l}\text { Faktor yang terbentuk dapat menjelaskan } \\
93,2 \% \text { varians dari variabel buah-buahan. }\end{array}$ \\
\hline 9. & Bahan lain & 0,976 & $\begin{array}{l}\text { Faktor yang terbentuk dapat menjelaskan } \\
97,6 \% \text { varians dari variabel bahan lain. }\end{array}$ \\
\hline 10. & Makanan jadi & 0,984 & $\begin{array}{l}\text { Faktor yang terbentuk dapat menjelaskan } \\
98,4 \% \text { varians dari variabel makanan } \\
\text { jadi. }\end{array}$ \\
\hline
\end{tabular}


Tabel 3. Nilai komunalitas setiap variabel (lanjutan)

\begin{tabular}{lll}
\hline 11. Minuman non & 0,975 & Faktor yang terbentuk dapat menjelaskan \\
alkohol & $97,5 \%$ varians dari variabel minuman non \\
& \\
& alkohol.
\end{tabular}

12. Tembakau dan $0,994 \quad$ Faktor yang terbentuk dapat menjelaskan alkohol $99,4 \%$ varians dari variabel tembakau dan alkohol.

\begin{tabular}{|c|c|c|c|}
\hline 13. & Biaya tinggal & 0,953 & $\begin{array}{l}\text { Faktor yang terbentuk dapat menjelaskan } \\
95,3 \% \text { varians dari variabel biaya tinggal. }\end{array}$ \\
\hline 14. & Bahan bakar & 0,948 & $\begin{array}{l}\text { Faktor yang terbentuk dapat menjelaskan } \\
94,8 \% \text { varians dari variabel bahan bakar. }\end{array}$ \\
\hline 15 . & $\begin{array}{l}\text { Perlengkapan } \\
\text { tangga }\end{array}$ & 0,936 & $\begin{array}{l}\text { Faktor yang terbentuk dapat menjelaskan } \\
93,6 \% \text { varians dari variabel perlengkapan } \\
\text { rumah tangga. }\end{array}$ \\
\hline
\end{tabular}

\begin{tabular}{llll}
\hline 16. & Penyelenggaraan & 0,980 & Faktor yang terbentuk dapat menjelaskan \\
rumah tangga & & $98 \%$ varians dari variabel \\
& & penyelenggaraan rumah tangga. \\
& & \\
\hline
\end{tabular}

17. Sandang laki-laki $\quad 0,973 \quad$ Faktor yang terbentuk dapat menjelaskan 97,3\% varians dari variabel sandang lakilaki.

18. Sandang perempuan $0,984 \quad$ Faktor yang terbentuk dapat menjelaskan $98,4 \%$ varians dari variabel sandang perempuan.

\begin{tabular}{lll}
\hline 19. Sandang anak & 0,961 & $\begin{array}{l}\text { Faktor yang terbentuk dapat menjelaskan } \\
96,1 \% \text { varians dari variabel sandang } \\
\text { anak. }\end{array}$ \\
& & \\
\hline 20. Sandang lain & 0,973 & Faktor yang terbentuk dapat menjelaskan \\
& $97,3 \%$ varians dari variabel sandang lain.
\end{tabular}


Tabel 3. Nilai komunalitas setiap variable (lanjutan)

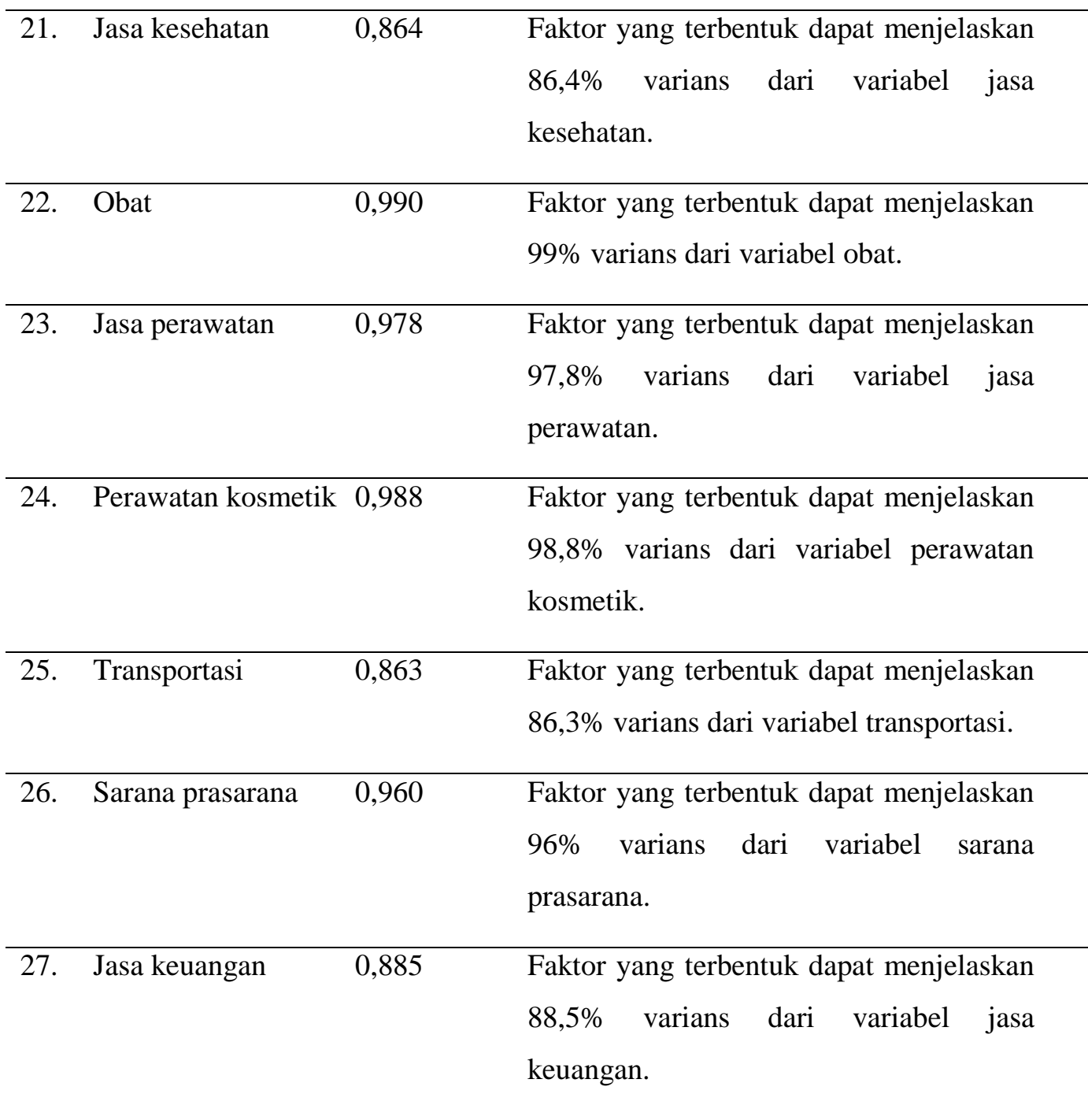

Berdasarkan output software SPSS, dapat dilihat bahwa faktor yang dapat terbentuk berdasarkan nilai eigenvalue lebih besar dari 1 ada dua faktor. Faktor pertama dan kedua memiliki nilai eigen berturut-turut sebesar 23,808 dan 1,222. Nilai persentase variansi diperoleh dari nilai eigen dibagi dengan banyak variabel. Faktor pertama sudah mampu menjelaskan 88,178\% dari variansi total. Apabila ditambah dengan memasukkan faktor kedua maka faktor kedua menjelaskan $4,525 \%$ dari total variansi. Sehingga total variansi yang disumbangkan oleh 2 faktor tersebut yakni 92,703\% dari variansi total. Selain melalui nilai eigen, jumlah faktor yang diekstraksi dapat dilihat dari scree plot yang diberikan oleh Gambar 1. 


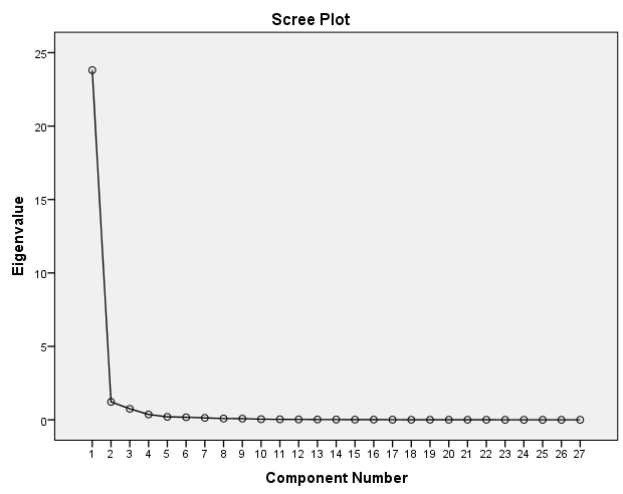

Gambar 1. Scree plot

Dari Gambar 1, dapat dilihat bahwa pada dua komponen awal plot turun secara tajam, setelah komponen kedua plot mengalami penurunan yang kurang signifikan. Sehingga dapat disimpulkan bahwa kemungkinan faktor yang dapat di ekstrak berjumlah dua faktor.

\subsection{Rotasi Faktor}

Rotasi faktor digunakan untuk mengelompokkan variabel ke dalam faktor yang memiliki korelasi tinggi dengan faktor tersebut. Berdasarkan output software SPSS, dapat dilihat bahwa seluruh faktor memiliki korelasi yang sangat tinggi dengan faktor pertama, dan memiliki korelasi yang rendah dengan faktor kedua. Namun, untuk menambah keyakinan, dilakukan rotasi faktor menggunakan metode varimax. Setelah dilakukan rotasi, hampir semua variabel memiliki korelasi yang seimbang antara faktor pertama dan kedua. Dengan menggunakan rotasi faktor pada data IHK Kota Semarang kurang dapat menjelaskan pengelompokkan variabel ke dalam faktor-faktor yang ada.

Faktor pertama memiliki korelasi yang sangat tinggi dengan semua variabel, maka cukup menggunakan faktor pertama saja. Karena dipilih 1 faktor saja, maka step ekstraksi diulangi dengan mengekstrak 1 faktor dan diperoleh kumulatif varian 88,509\% dengan nilai eigen 23,012 .

\subsection{Interpretasi faktor}

Faktor yang terbentuk hanya 1 yakni faktor yang sangat mempengaruhi IHK Kota Semarang dengan 27 variabel. Faktor tersebut yakni faktor kebutuhan primer masyarakat perkotaan. Kota Semarang menjadi pusat ekonomi, sosial, dan budaya di Provinsi Jawa Tengah tentu saja menjadi pusat dari segala kegiatan tersebut. Oleh karena itu, kebutuhan primer tidak cukup sandang, pangan, dan papan saja, melainkan barang dan kebutuhan 
lain yang memiliki nilai ekonomi yang mampu menunjang kehidupan masyarakat Kota Semarang. Faktor kebutuhan primer ini sangat berpengaruh terhadap IHK Kota Semarang.

\section{Kesimpulan}

Berdasarkan hasil analisis faktor yang dilakukan terhadap Indeks Harga Konsumen (IHK) Kota Semarang pada periode Januari 2014 hingga Agustus 2018, terdapat 3 variabel yang direduksi yakni variabel lemak dan minyak, bumbu, dan komunikasi pengiriman. Dapat disimpulkan bahwa hanya terdapat 1 faktor yang terbentuk yakni faktor kebutuhan primer masyarakat perkotaan. Faktor kedua yang terbentuk tidak terlalu signifikan dalam memberikan pengaruh, dan dilihat dari nilai variansi faktor pertama sudah cukup untuk mewakili. Faktor pertama yakni kebutuhan primer masyarakat perkotaan khususnya Kota Semarang yang mana menjadi pusat ekonomi, sosial, dan pemerintahan di Jawa Tengah. Faktor tersebut dapat menjelaskan 85,09\% total variansi. Hal ini diperkuat dengan korelasi semua variabel yang sangat tinggi dengan faktor pertama.

\section{Daftar Pustaka}

[1] Badan Pusat Statistik Indonesia. Laporan Perekonomian Indonesia 2008. BPS Indonesia: Jakarta. 2008.

[2] Santoso, S. Buku Latihan SPSS Multivariat. Elex Media Komputindo: Jakarta. 2003.

[3] Kachigan, dan Kash,S. Statistical Analysis. Radius Press: New York. 1986.

[4] Johnson, R. A., dan Wichern, D. W. Applied Multivariate Statistical Analysis. Prentice Hall: New Jersey. 2002.

[5] Kaiser, H. F. An index of factor simplicity. Psychometrika. 39: 31-36. 1974.

[6] Sharma, S. Applied Multivariate Techniques, John Wiley and Sons, Inc: New-York. 1996. 